\title{
Surface heterogeneity impacts on boundary layer dynamics via energy balance partitioning
}

\author{
N. A. Brunsell ${ }^{1}$, D. B. Mechem ${ }^{1}$, and M. C. Anderson ${ }^{2}$ \\ ${ }^{1}$ Dept. of Geography, University of Kansas, Lawrence, KS, USA \\ ${ }^{2}$ Hydrology and Remote Sensing Laboratory, USDA. Beltsville, MD, USA
}

Received: 22 June 2010 - Published in Atmos. Chem. Phys. Discuss.: 23 July 2010

Revised: 22 March 2011 - Accepted: 6 April 2011 - Published: 11 April 2011

\begin{abstract}
The role of land-atmosphere interactions under heterogeneous surface conditions is investigated in order to identify mechanisms responsible for altering surface heat and moisture fluxes. Twelve coupled land surface - large eddy simulation scenarios with four different length scales of surface variability under three different horizontal wind speeds are used in the analysis. The base case uses Landsat ETM imagery over the Cloud Land Surface Interaction Campaign (CLASIC) field site for 3 June 2007. Using wavelets, the surface fields are band-pass filtered in order to maintain the spatial mean and variances to length scales of $200 \mathrm{~m}$, $1600 \mathrm{~m}$, and $12.8 \mathrm{~km}$ as lower boundary conditions to the model (approximately 0.25, 1.2 and 9.5 times boundary layer height). The simulations exhibit little variation in net radiation. Rather, there is a pronounced change in the partitioning of the surface energy between sensible and latent heat flux. The sensible heat flux is dominant for intermediate surface length scales. For smaller and larger scales of surface heterogeneity, which can be viewed as being more homogeneous, the latent heat flux becomes increasingly important. The simulations showed approximately $50 \mathrm{Wm}^{-2}$ difference in the spatially averaged latent heat flux. The results reflect a general decrease of the Bowen ratio as the surface conditions transition from heterogeneous to homogeneous. Air temperature is less sensitive to variations in surface heterogeneity than water vapor, which implies that the role of surface heterogeneity may be to maximize convective heat fluxes through modifying and maintaining local temperature gradients. More homogeneous surface conditions (i.e. smaller length scales), on the other hand, tend to maximize latent heat flux. The intermediate scale $(1600 \mathrm{~m})$ this does not hold, and is a more complicated interaction of scales.
\end{abstract}

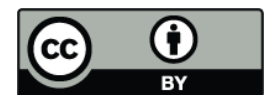

Correspondence to: N. A. Brunsell (brunsell@ku.edu)
Scalar vertical profiles respond predictably to the partitioning of surface energy. Fourier spectra of the vertical wind speed, air temperature and specific humidity $(\tilde{w}, \tilde{T}$ and $\tilde{q})$ and associated cospectra $(\tilde{w} \tilde{T}, \tilde{w} \tilde{q}$ and $\tilde{T} \tilde{q})$, however, are insensitive to the length scale of surface heterogeneity, but the near surface spectra are sensitive to the mean wind speed.

\section{Introduction}

Understanding the role of surface heterogeneity on landatmosphere interactions is of prime importance for both routine monitoring of fluxes from remote sensing platforms as well as assessing the local impacts of global climate change. Surface heterogeneity is fundamentally an issue of scale, in the sense of modeling and observational resolution (Brunsell and Gillies, 2003; Raupach and Finnigan, 1995; Anderson et al., 2003). Numerous efforts, ranging from the effective parameters technique (Lhomme et al., 1994; Chehbouni et al., 1995) to the mosaic approach (Koster and Suarez, 1992), have attempted to address the issue of scaling land surface parameters to ascertain areally averaged fluxes. A different approach quantifies the blending height (Mason, 1988) and assesses how the scale of surface heterogeneity is related to mixing within the atmospheric boundary layer (ABL) (Mahrt, 2000; Claussen, 1990; Molod et al., 2003). However, a general understanding of the role of land surface heterogeneity remains elusive.

Large eddy simulation (LES) has emerged as a viable tool for investigating issues associated with surface heterogeneity and land-atmosphere interactions (Stevens and Lenschow, 2001). These issues range from the basic theoretical applicability of Monin-Obukhov similarity theory (Khanna and Brasseur, 1997) to the role of land surface heterogeneity on boundary layer dynamics (Lin and Glendening, 2002) and

Published by Copernicus Publications on behalf of the European Geosciences Union. 
the role of surface roughness and blending heights (Bou-Zeid et al., 2004).

Under no-wind conditions, Hadfield et al. (1991) found that turbulence was stronger under higher sensible heating. This association leads to the development of a circulation pattern which under light winds become even further weakened, and an alteration of the turbulent profiles (Hadfield et al., 1992). Avissar et al. (1998) found the impact of surface heterogeneity on the heat fluxes was reduced particularly for dry conditions under light wind conditions. Under moderate winds almost all impacts of surface heterogeneity were reduced. Avissar et al. (1998) also found that surface heterogeneity influenced potential temperature much more than humidity. This result led them to conclude that surface patches must be on the order of $5-10 \mathrm{~km}$ in order to be significant. Shen and Leclerc (1995) and Letzel and Raasch (2003) confirmed these results and also found the existence of mesoscale circulations when the scales of surface heterogeneity reach approximately $5 \mathrm{~km}$.

The scales at which surface heterogeneity impacts the boundary layer are generally considered to be on the order of the boundary layer height $\left(z_{i}\right)$. However, Hechtel et al. (1990) compared heterogeneous (length scales between 450-900 m) and homogeneous LES results under light wind conditions and found no impact of surface heterogeneity on boundary layer dynamics. Courault et al. (2007) did observe the formation of an inland breeze with large patches and varying soil moisture. They also noted a variation in surface energy fluxes on the order of 5\% that were dependent upon the surface configuration. Raasch and Harbusch (2001) found that the impact was due not to the configuration of the patches but rather the large amplitude of the heat flux. Using an LES coupled with a land surface model, Patton et al. (2005) found that scales on the order of 4 to 9 times the boundary layer height induced the largest magnitude impacts between wet and dry surface patches. They noted that variations in scale impacted total flux minimally, but the relative contribution to scalar fluxes from organized circulations varied with the patch size. They also concluded that there was little impact of surface heterogeneity on the entrainment rate.

However, as discussed by Prabha et al. (2007), the orientation of surface heterogeneity with respect to the geostrophic wind is important. Stationary circulations may develop, which can enhance entrainment and down-wind scalar diffusion. They also note, that these circulations could account for the "energy-balance closure" problem observed with the use of eddy covariance measurements (Twine et al., 2000; Foken, 2008). This led Huang et al. (2008) to conduct an LES study of the energy balance problem. They concluded that the interaction between surface heterogeneity, boundary layer height and entrainment can alter the scalar transport of top-down (from above the boundary layer) and bottom-up (originating at the surface) diffusion and can account for the observed flux imbalance.
Recently, researchers have begun to assess the impact of surface heterogeneity with realistic surface conditions. This effort has largely come through the use of surface remote sensing techniques (Albertson et al., 2001; Timmermans et al., 2008). Coupling remote sensing observations to a land surface model to provide the lower boundary conditions allows for explicitly modeling of feedback mechanisms between the surface and the atmosphere (Kustas and Albertson, 2003). Bertoldi et al. (2008) used this approach to assess the errors associated with remotely sensed flux algorithms which often rely on the assumption of horizontally homogeneous near-surface atmospheric properties. Huang and Margulis (2009) examined the SMACEX site near Ames, Iowa and found that the potential temperature was more sensitive to the scale of surface heterogeneity than was the humidity. They attribute this difference to the heterogeneity in the surface sensible heat flux. They state that "organized surfaces provide higher spatially averaged thermal flux than homogeneous/random surfaces". This conclusion was confirmed by Huang et al. (2009) who found that homogenous soil moisture conditions led to an underestimation of sensible heat flux $(H)$ and an overestimation of latent heat flux (LE) due to an underestimation of the aerodynamic conductance.

Huang et al. (2009) discovered a scalar dissimilarity in which the eddy diffusivities for different scalars (humidity, carbon and temperature) varied due to heterogeneity in surface moisture and entrainment. Scalar dissimilarity has been linked to surface heterogeneity induced by vegetation phenological patterns (Williams et al., 2007). Lamaud and Irvine (2006) linked scalar dissimilarity and the relative efficiency of heat and water vapor transport to the Bowen ratio $(\beta=H / \mathrm{LE})$.

This dependence on Bowen ratio implies that $\beta$ may be a metric by which to assess the role of land surface heterogeneity and boundary layer interactions. Friedrich et al. (2000) found that surface heterogeneity altered the net radiation (primarily through an albedo impact) and thus $\beta$. While different land cover classes will alter the surface albedo and thus impact the net radiation, the impact of surface heterogeneity may in fact be more subtle. The work of Jones and Brunsell (2009) showed through regional climate simulations that the impact was primarily on the resultant partitioning of the fluxes (i.e. on $\beta$ itself), even under cases where there was little change in the net radiation and no change in land cover. This was also the conclusion of Teuling and Seneviratne (2008) when assessing the impacts of remotely sensed surface albedo changes and the resultant precipitation over Europe during the 2003 heat wave.

The objective of this paper is to examine the effects of land surface heterogeneity in vegetation and soil moisture on surface-atmosphere exchanges of mass and energy. Our hypothesis is that energy balance partitioning is the mechanism by which land surface heterogeneity in moisture, vegetation and surface temperature alters atmospheric boundary layer dynamics. Understanding the nature of surface atmosphere 
coupling is vitally important for assessing local responses to global climate change.

\section{Methodology}

\subsection{Numerical model description}

We employ the Advanced Regional Prediction System (ARPS version 5.2.8, Xue et al., 2000, 2001) in an LES framework interactively coupled to a land surface model. ARPS was intended for idealized cloud-scale simulation and mesoscale numerical weather prediction but has been used successfully as an LES in a region of highly complex topography (Chow et al., 2006; Weigel et al., 2006). ARPS is based on fully compressible, nonhydrostatic dynamics and uses mode-splitting to integrate the acoustically active terms on small timesteps. We employ a typical LES experimental framework. Fourth order horizontal and second order vertical advection are used for both momentum and scalars. The large timestep is accomplished via leapfrog differencing with a Robert-Asselin time filter, while the small timestep uses forward-backward differencing with a semi-implicit solution in the vertical. Our domain is $128 \times 128 \times 100$ points, with doubly periodic boundary conditions in the horizontal. Horizontal grid spacing is $100 \mathrm{~m}$, while the vertical mesh is stretched according to $\Delta z \sim z^{3}$ and ranges from $10 \mathrm{~m}$ at the surface to $40 \mathrm{~m}$ at a height of $1200 \mathrm{~m}$. This grid configuration results in a domain with dimension $12.5 \times 12.5 \times 3.9 \mathrm{~km}^{2}$. The upper boundary is a rigid lid, with a Rayleigh damping (sponge) layer applied to the uppermost $700 \mathrm{~m}$ of the domain. The sub-grid scale (SGS) is parameterized by the 1.5-order turbulence closure model of Deardorff (1980), with dissipation coefficients following Moeng and Wyngaard (1988).

ARPS is described for use as an LES by several other studies (e.g. Vinkovic et al., 2006; Chow et al., 2006). Because ARMS employs a fully-compressible dynamical framework and a curvilinear coordinate system, the resulting governing equations are far more complicated and cluttered than those in a typical LES (see Xue et al., 2000, Eqs. 1-7). However, for completeness, we provide here a brief overview of the LES equation set by following the approach of (Vinkovic et al., 2006) and distilling the ARPS governing equations down to their barest form applicable to our idealized experimental configuration. The LES governing equations for the filtered (resolved) fields (denoted by the tilde) are given in standard Einstein notation as:

$$
\begin{aligned}
& \frac{\partial \widetilde{u_{i}}}{\partial t}+\tilde{u_{j}} \frac{\partial \widetilde{u_{i}}}{\partial x_{j}}=-\frac{1}{\rho} \frac{\partial \widetilde{p}}{\partial x_{i}}+\frac{\partial}{\partial x_{j}}\left(v\left(\frac{\partial \tilde{u_{i}}}{\partial x_{j}}+\frac{\partial \tilde{u_{j}}}{\partial x_{i}}\right)-\tau_{i j}^{r}\right)+\widetilde{B}_{i} \\
& \frac{\partial \widetilde{\Delta p}}{\partial t}+\tilde{u_{j}} \frac{\partial \widetilde{\Delta p}}{\partial x_{j}}=\frac{\rho}{c^{2}}\left(\frac{1}{\tilde{T}} \frac{\partial \tilde{T}}{\partial t}-\frac{\partial \widetilde{u_{i}}}{\partial x_{i}}\right) \\
& \frac{\partial \widetilde{q}}{\partial t}+\tilde{u_{j}} \frac{\partial \widetilde{q}}{\partial x_{j}}=-\frac{\partial \pi_{i}^{q}}{\partial x_{j}}+e
\end{aligned}
$$

Equation (1) is the conservation of momentum, where the velocity $u_{i}$ in the $i=1,2,3$ direction corresponding to the $x$ (streamwise velocity $u$ ), $y$ (spanwise velocity $v$ ), and $z$ (vertical velocity $w$ ) direction, $p$ is the total pressure, $v$ is the molecular kinematic viscosity, $\rho$ is the density, $\tau$ denotes the effect of the subgrid stress on the resolved scales, and $B$ includes contributions from buoyancy and the Coriolis force. The pressure equation is shown in Eq. (2), where $\Delta p$ is the deviation from the undisturbed, hydrostatic base state, $T$ is the potential temperature and $c$ is the speed of sound. Equation (3) shows the conservation of humidity, where the $\pi$ term in the humidity equation accounts for any subgrid scale fluxes while the $e$ term represents the resolved source/sink (e.g. evapotranspiration into the atmosphere from the land surface scheme).

The land surface scheme used in ARPS is explained in detail in Xue et al. (2001). For these simulations we chose the two layer surface energy balance model of Noilhan and Planton (1989) to represent the interactive exchange of water and energy between the land and atmosphere. Soil layer depth was set to $1 \mathrm{~m}$, which resulted in reasonable response timescales for warming and drying of the soil during the day. Soil physical characteristics and the selection of soil initial conditions are described below. The soil model was coupled with a simple radiation parameterization that calculated the incoming and outgoing radiative streams at the surface. Although a greatly simplified treatment of radiation, it captures the essential physics of boundary layer radiative transfer while being far less expensive computationally than twoor four-stream approaches integrated over the depth of the atmosphere.

Initial conditions are horizontally homogeneous, with idealized atmospheric profiles based a composite of the KOUN (Norman, OK) 12:00 UTC and 00:00 UTC soundings from 3-4 June 2007, respectively. These profiles are used for the Geostrophic forcing. For simplicity of analysis and interpretation, the $v$ component of this forcing is set to zero in these simulations.

\subsection{Generation of the surface fields}

The LES runs are conducted over the area near Ft. Cobb, Oklahoma. This represents one of the central areas of the Cloud Land Surface Interaction Campaign (CLASIC) conducted in summer, 2007. Landsat ETM imagery from 3 June 2007 is used to compute the spatially distributed surface temperature, moisture and roughness fields. This date is prior to the beginning of the intensive field portion of the CLASIC project.

The fractional vegetation cover (Fr) is computed as a scaled version of the Normalized Difference Vegetation Index (NDVI) (Gillies and Carlson, 1995):

$\mathrm{Fr}=\left(\frac{\mathrm{NDVI}-\mathrm{NDVI}_{0}}{\mathrm{NDVI}_{\mathrm{M}}-\mathrm{NDVI}_{0}}\right)^{2}$ 
where $\mathrm{NDVI}_{0}$ and $\mathrm{NDVI}_{\mathrm{M}}$ are the NDVI values corresponding to bare soil and fully vegetated pixels respectively.

Pixel level near surface soil moisture values $\left(M_{0}\right)$ are derived from the fractional vegetation-surface temperature ( $\mathrm{Fr}$ $T_{\mathrm{S}}$ ) space using the "triangle" method (Gillies and Carlson, 1995; Brunsell and Gillies, 2003). This method consists of fitting a linear model to the $\mathrm{Fr}$ and $T_{\mathrm{s}}$ values assuming the presence of a warm, dry edge ( $0 \%$ relative soil moisture) and a cool, moist edge ( $100 \%$ relative soil moisture). These values are then translated into an actual volumetric soil moisture by scaling the degree of saturation between wilting point $\left(0.09 \mathrm{~m}^{3} \mathrm{~m}^{-3}\right)$ and field capacity $\left(0.35 \mathrm{~m}^{3} \mathrm{~m}^{-3}\right)$.

Surface roughness for momentum $z_{0, \mathrm{~m}}$ is derived from the NDVI (van der Kwast et al., 2009):

$z_{0, \mathrm{~m}}=0.005+0.5\left(\frac{\mathrm{NDVI}}{\mathrm{NDVI}_{\mathrm{M}}}\right)^{2.5}$

This was chosen to resolve the heterogeneous nature of the surface vegetation. While a majority of the surface is agricultural, there are some portions of the study area which exhibit tree vegetation.

The spatial distribution of percentage of vegetation, surface radiometric temperature, soil moisture, and roughness length, all quantities calculated from the Landsat imagery, constitute the initial conditions for the control simulation. In order to isolate the effects of various surface length scales on land-atmosphere interactions, we performed a suite of sensitivity simulations using bandpass-filtered surface fields obtained by wavelet multi-resolution analysis. In principle this wavelet decomposition is similar to traditional bandpass filtering using Fourier analysis methods, but for this application the wavelet approach is far superior, since it preserves the specific character of the heterogeneity (location of specific fields and ponds, for example) in the surface fields.

Wavelet multi-resolution analysis was conducted on the Fr, $T_{\mathrm{S}}$ and $M_{0}$ fields in order to derive the band pass filtered version used for initialization of the LES. A one-dimensional wavelet transform is conducted via the translation and dilation of a mother wavelet $\psi$ across a data set $f$ as a function of time $t$ :

$W(m, n)=\lambda_{0}^{-m / 2} \int_{-\infty}^{\infty} f(t) \psi\left(\lambda_{0}^{-m} t-n t_{0}\right) d t$

where $\lambda_{0}$ is the initial scale, $m$ is the dilation and $n$ is the translation. In practice, the integration would be conducted over the full domain of interest and not to infinity. The wavelet is given by:

$\psi_{m, n}(t)=\frac{1}{\sqrt{\lambda_{0}^{m}}} \psi\left(\frac{t-n t_{0} \lambda_{0}^{m}}{\lambda_{0}^{m}}\right)$

For our purposes, we must extend this analysis to twodimensional fields in order to construct the spatially explicit surface fields. The two-dimensional wavelet transform is conducted as three one-dimensional wavelet transforms (Kumar and Foufoula-Georgiou, 1993):

$$
\begin{aligned}
& \Psi^{1}(x, y)=\phi(x) \psi(y) \\
& \Psi^{2}(x, y)=\phi(y) \psi(x) \\
& \Psi^{3}(x, y)=\psi(x) \psi(y)
\end{aligned}
$$

where $\phi$ is the scaling function.

The discrete detailed coefficients at each scale can be calculated from the inner product of the spatial data field $f(x, y)$ and the wavelet transforms above:

$$
\begin{aligned}
& Q_{m}^{\mathrm{d} 1} f=\left(f, \Psi_{m n k}^{1}\right) \\
& Q_{m}^{\mathrm{d} 2} f=\left(f, \Psi_{m n k}^{2}\right) \\
& Q_{m}^{\mathrm{d} 3} f=\left(f, \Psi_{m n k}^{3}\right)
\end{aligned}
$$

This analysis returns band-pass filtered versions of the dataset at each scale of interest. Therefore, the original dataset $(f(x, y))$ can be reconstructed from the coarsest scale (i.e. average) and the residual fluctuations $\left(f^{\prime}(x, y)=\right.$ $\left.\sum Q_{m}^{d_{i}} f\right)$ at each point $(x, y)$ :

$f(x, y) \approx \overline{f_{m}(x, y)}+\sum_{m \geq m_{0}} f_{m}^{\prime}(x, y)$

From the wavelet decomposed values of the remotely sensed fields, we rescale the values to ensure that each field $\left(\mathrm{Fr}, T_{\mathrm{S}}\right.$ and $\left.M_{0}\right)$ will have the same range as the original simulations:

$f_{r, i}(x, y)=\left(f_{\max }-f_{\min }\right) f_{\mathrm{d}, i}(x, y)+f_{\min }$

where $f_{\mathrm{r}, i}(x, y)$ is the reconstructed field at scale $i$, location $(x, y)$ from the wavelet decomposed value $\left(f_{\mathrm{d}, i}(x, y)\right)$, and $f_{\max }$ and $f_{\min }$ are the spatial maximum and minimum values of the original field.

We conducted the wavelet decomposition over seven scales for the Fr, $T_{\mathrm{S}}$ and $M_{0}$ fields. The finest scale (corresponding to a length scale of $200 \mathrm{~m}$ ), an intermediate scale (corresponding to a length scale of $1600 \mathrm{~m}$ ) and the coarsest scale (corresponding to $12800 \mathrm{~m}$ length scale) were used as initial conditions to the LES for simulations. The fractional vegetation was held constant, while the surface temperature and moisture were predicted from the model at each time step following initialization. These decomposed fields represent band-pass filtered versions of the original case which had a resolution of $100 \mathrm{~m}$ (containing contributions from all scales). These levels of decomposition will be referred to by the dominant length scale $(200,1600$ or $12800 \mathrm{~m}$ respectively) and in the original case by the initial resolution (100 m).

These levels of decomposition were chosen to give a broad range of the surface scalings: one case with heterogeneity much smaller than the boundary layer height, one case on the order of boundary layer height, and one case with significantly larger heterogeneity. The boundary layer height for these simulations is approximately $1350 \mathrm{~m}$, so the chosen 
(a)

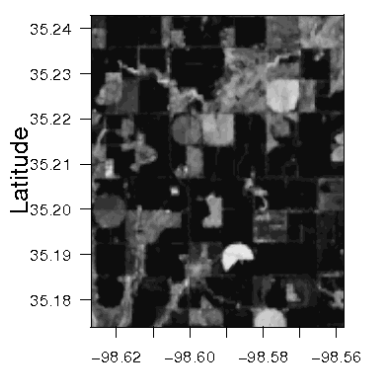

(c)

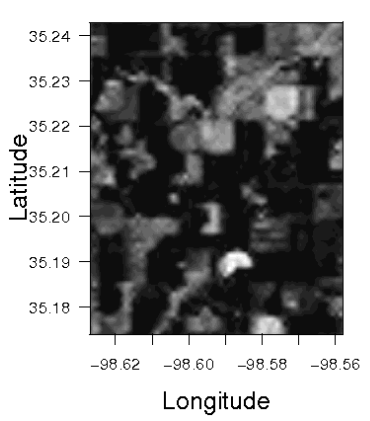

(b)

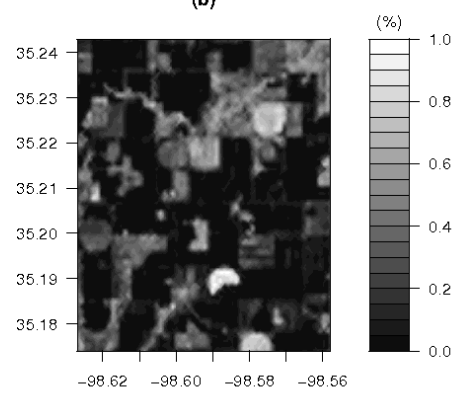

(d)

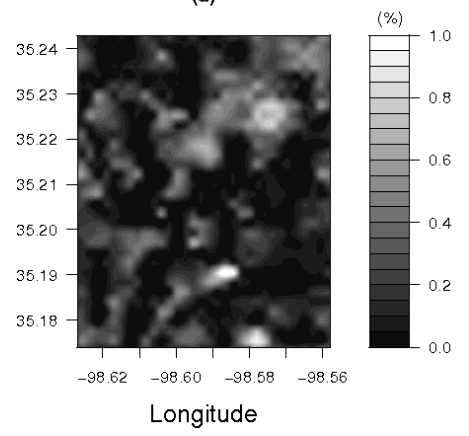

Fig. 1. (a) Original Landsat fractional vegetation (Fr, [\%]) field $(100 \mathrm{~m})$ and low pass filtered versions at select spatial resolutions (b) $200 \mathrm{~m}$, (c) $1600 \mathrm{~m}$ and (d) $12800 \mathrm{~m}$.

surface length scales correspond to approximately $0.25,1.2$ and 9.5 times boundary layer height.

In addition to the reconstructed surface fields, we altered the horizontal wind speeds for each of the scales. In the first case, we use the observed sounding and then increase each level by adding 3 and $6 \mathrm{~m} \mathrm{~s}^{-1}$ to the initial zonal wind speed. When combined with the original surface fields run under the three different wind speed scenarios results in a total of 12 LES simulations used in this analysis.

\section{Results}

\subsection{Observed surface heterogeneity}

The Landsat fractional vegetation is shown in Fig. 1. In addition, three levels of low-pass filters are shown to illustrate the nature of surface heterogeneity used in this analysis and which will contribute to the land-atmosphere interactions in the simulations. In order to ascertain a quantitative perspective of the impact of different length scales of surface variability, we computed the wavelet spectra for the radiometric temperature and the fractional vegetation (Fig. 2). The horizontal (East-West) and vertical (North-South) components each show a maximum in the wavelet variance at $1600 \mathrm{~m}$ while the diagonal component of the spectra shows a slightly smaller length scale around $800 \mathrm{~m}$. Therefore we conclude that the length scale of surface heterogeneity is on the order
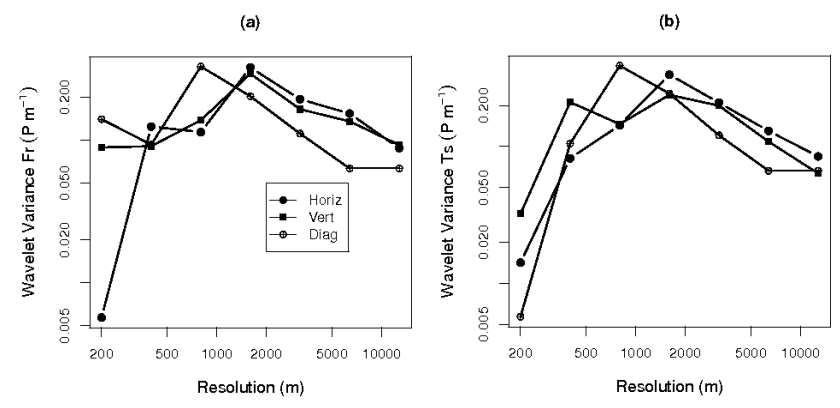

Fig. 2. Two dimensional wavelet spectra $\left[\mathrm{Pm}^{-1}\right]$ for the (a) fractional vegetation and (b) radiometric temperature fields.

of $1-2 \mathrm{~km}$ which is on on the same order as the boundary layer height.

\subsection{Impact of variation in surface boundary conditions}

In order to examine the impacts of surface heterogeneity on boundary layer dynamics, we initialize the LES with the original surface conditions, as well as band pass filtered versions of the surface at small $\left(200 \mathrm{~m} \approx 0.25 z_{i}\right)$, medium $\left(1600 \mathrm{~m} \approx 1.2 z_{i}\right)$ and large $\left(12.8 \mathrm{~km} \approx 9.5 z_{i}\right)$ spatial scales of heterogeneity. The bandpass filtered simulations include surface heterogeneity contributions from specific scales only. The medium case includes the dominant length scale of surface heterogeneity, while the original case runs include contributions from all scales.

Figure 3 shows the spatial distribution of surface temperature, soil moisture and latent heat fluxes after $8 \mathrm{~h}$ of simulation. The surface temperature generally retains the imposed scale of heterogeneity from the band pass filtered versions of the input data used as initial conditions. The soil moisture field retains its overall (symmetric) variability at the end of the simulations due largely to the fact that the length of the simulations is not sufficiently long to evaporate significant amounts of moisture. As an example of the surface fluxes, the final latent heat fluxes for each scenario are also shown in Fig. 3. The largest and finest scales are more similar (i.e. homogeneous) by the end of the simulation, while the original simulations all exhibit spatial variance more similar to the intermediate scale. Despite having the most homogeneous soil moisture fields, the fluxes at largest and smallest scales are nevertheless heterogeneous, owing to the small-scale variability in atmospheric properties present in any convective boundary layer. Recall that the scaling of the initial surface fields preserves the spatial mean and variance of the $\mathrm{Fr}, M_{0}$ and $T_{\mathrm{s}}$ fields. Thus, the total vegetated area and bare soil contributing as sources of latent heat flux is the same in all simulations, only the spatial configuration is different.

In order to understand better the effect of the bandpass filtering on the surface fields, we examine the spatial probability density functions (PDFs) for soil moisture $(\theta)$ and surface temperature $\left(T_{\mathrm{S}}\right)$ corresponding to the final simulation time 
(a)

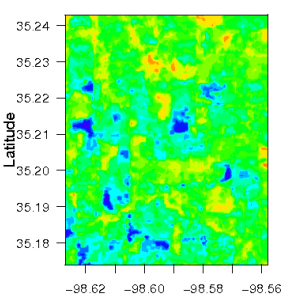

(e)

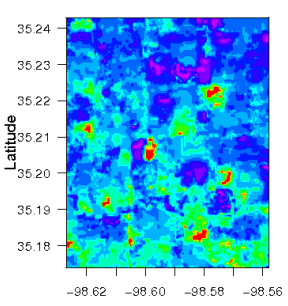

(i)

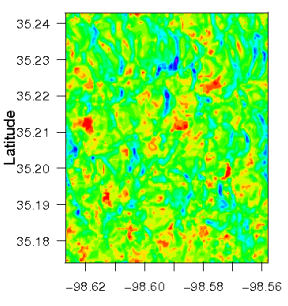

Longitude (b)

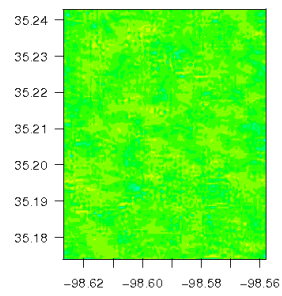

(1)

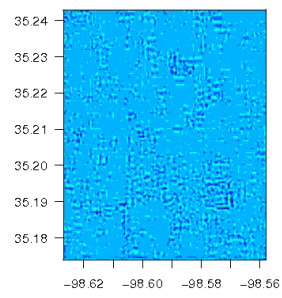

(j)

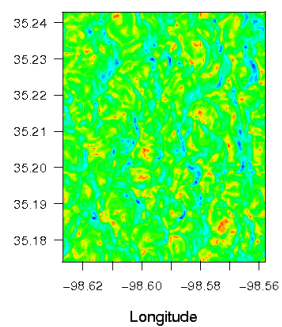

(c)

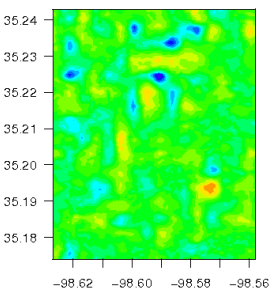

(g)

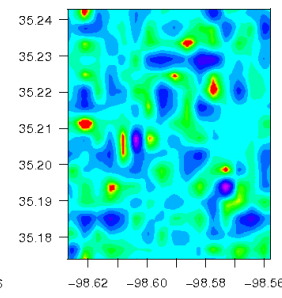

(k)

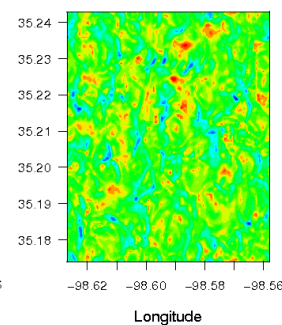

(d)

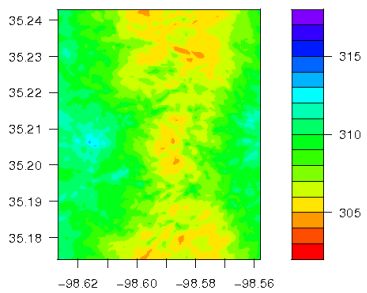

(h)

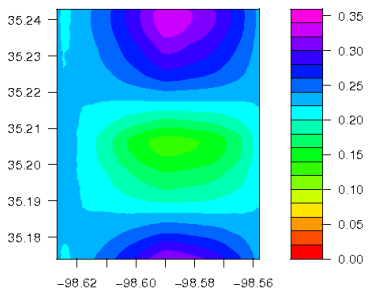

(I)

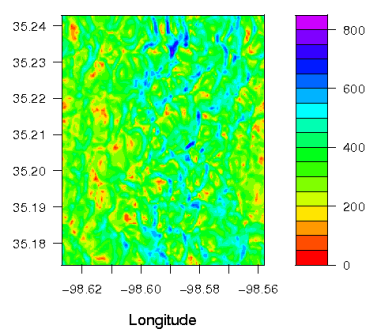

Fig. 3. (a-d) Surface temperatures $[\mathrm{K}]$ at $8 \mathrm{~h}$ of simulation time under (a) using LandSAT ETM imagery (b) surface conditions band pass filtered to a length scale of $200 \mathrm{~m}$, (c) band pass filtered to $1600 \mathrm{~m}$ and (d) band pass filtered to $12800 \mathrm{~m}$. (e-h) The same for soil moisture $\left[\mathrm{kg} \mathrm{kg}^{-1}\right]$ and (i-l). The same for surface latent heat flux $\left[\mathrm{W} \mathrm{m}^{-2}\right]$.

(Fig. 4). The observed simulation is characterized by the most homogeneous soil moisture PDF, with the mean values being approximately equal across all cases (Table 1). The $T_{\mathrm{S}}$ values for the $200 \mathrm{~m}$ and $1600 \mathrm{~m}$ length scales and are approximately normally distributed, with the $1600 \mathrm{~m}$ simulation exhibiting a slightly higher mean. The coarsest scale $(12.8 \mathrm{~km})$ shows a wide variance in $T_{\mathrm{S}}$, approaching the variability observed in the original case with a slightly lower mean temperature gradient. In addition to the PDFs, we show the "triangle" plots similar to Gillies et al. (1997) and Brunsell and Gillies (2003). These scatterplots are shown in Fig. 5 for the original as well as the three levels of decomposition. While these plots show the same data as used in the spatial fields (Fig. 3) and the PDFs (Fig. 4), they illustrate the dependent nature of the surface fields as processed by the land surface scheme.

Time series of the spatially averaged sensible heat and latent heat fluxes are shown in Fig. 6. In addition, the net radiation $\left(<R_{\mathrm{n}}>\right)$ and Bowen ratio $(<\beta>)$ are also shown. The surface net radiation is remarkably consistent across all runs, while the partitioning between the turbulent fluxes is a function of the spatial scale of surface heterogeneity (as exhibited by $<\beta>$ ). The larger mean values of $T_{\mathrm{S}}$ in the original and
Table 1. Spatial means and variances for surface temperature $\left(T_{\mathrm{S}}\right.$, $[\mathrm{K}])$ and soil moisture $\left(\theta,\left[\mathrm{kg} \mathrm{kg}^{-1}\right]\right)$ at the end of each simulation.

\begin{tabular}{lrrrrr}
\hline Wind & $\begin{array}{r}\text { Scale } \\
\mathrm{m}\end{array}$ & $\begin{array}{r}<T_{\mathrm{S}}> \\
\mathrm{K}\end{array}$ & $\begin{array}{r}\sigma^{2} T_{\mathrm{s}} \\
\mathrm{K}^{2}\end{array}$ & $\begin{array}{r}<\theta> \\
\mathrm{kg} \mathrm{kg}^{-1}\end{array}$ & $\begin{array}{r}\sigma^{2} \theta \\
\left(\mathrm{kg} \mathrm{kg}^{-1}\right)^{2}\end{array}$ \\
\hline$u_{1}$ & 100 & 309.36 & 4.33 & 0.23 & 0.0024 \\
& 200 & 308.24 & 0.76 & 0.23 & 0.0002 \\
& 1600 & 309.19 & 2.04 & 0.21 & 0.0012 \\
& 12800 & 308.06 & 3.15 & 0.23 & 0.0017 \\
\hline$u_{3}$ & 100 & 307.07 & 4.97 & 0.22 & 0.0030 \\
& 200 & 306.31 & 0.54 & 0.22 & 0.0003 \\
& 1600 & 307.34 & 2.17 & 0.21 & 0.0019 \\
& 12800 & 306.13 & 3.15 & 0.22 & 0.0019 \\
\hline$u_{6}$ & 100 & 305.38 & 5.65 & 0.21 & 0.0043 \\
& 200 & 304.87 & 0.50 & 0.22 & 0.0004 \\
& 1600 & 305.89 & 2.33 & 0.18 & 0.0029 \\
& 12800 & 304.62 & 3.85 & 0.22 & 0.0023 \\
\hline
\end{tabular}




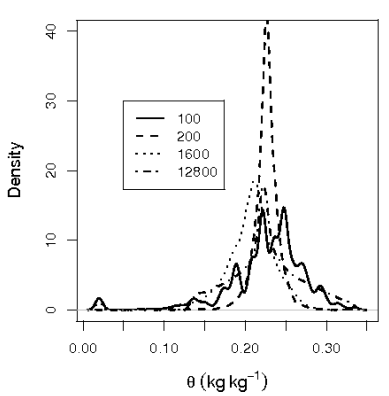

(b)

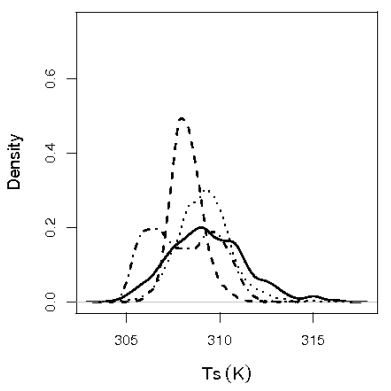

Fig. 4. Spatial probability density functions of (a) soil moisture $(\theta$, $\left.\left[\mathrm{kg} \mathrm{kg}^{-1}\right]\right)$ and $(\mathbf{b})$ the surface temperature $\left(T_{\mathrm{S}},[\mathrm{K}]\right)$ for light wind speed scenario at the final time step for different levels of decomposition.

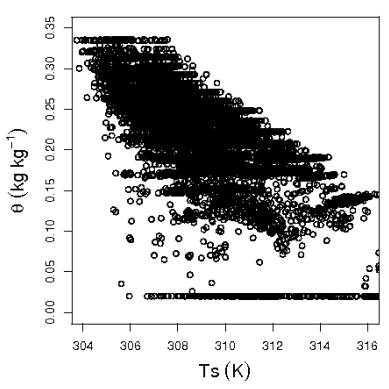

(c)

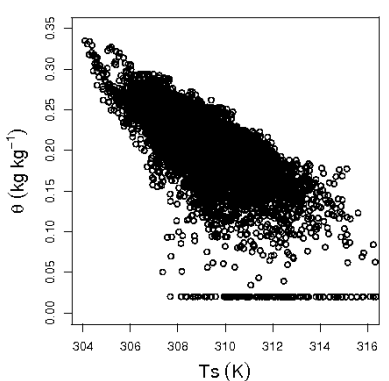

(b)

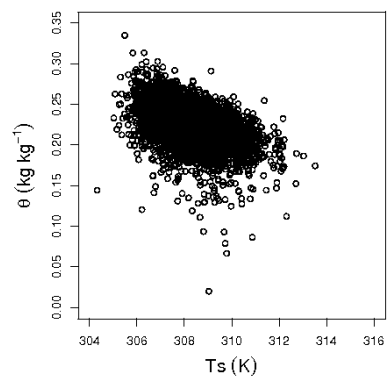

(d)

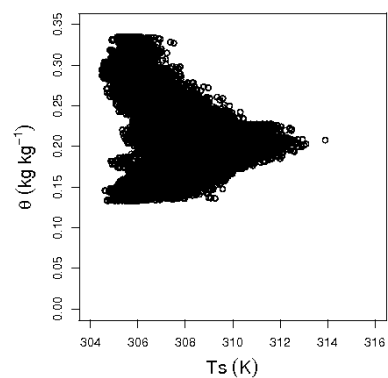

Fig. 5. Scatterplots of soil moisture $\left(\theta,\left[\mathrm{kg} \mathrm{kg}^{-1}\right]\right)$ and surface temperature $\left(T_{\mathrm{s}},[\mathrm{K}]\right)$ for low wind speed scenario at the final time step for different levels of decomposition (a) $100 \mathrm{~m}$ (b) $200 \mathrm{~m}$ (c) $1600 \mathrm{~m}$ and (d) $12800 \mathrm{~m}$.

$1600 \mathrm{~m}$ cases (Fig. 4) are consistent with the greater sensible heat fluxes shown in Fig. 6.

The more "homogeneous" cases of the finest and coarsest scales are generally similar to one another and exhibit smaller values of Bowen ratio than the more intermediate scales (both the original surface and the $1600 \mathrm{~m}$ simulations). This distinction translates into separations in the latent heat flux with the finest and coarsest scales exhibiting larger latent heat fluxes. Note that Huang et al. (2009) also observed alterations to the energy balance partitioning as a function of surface length scale, but in their case the sensible heat flux in-

(a)

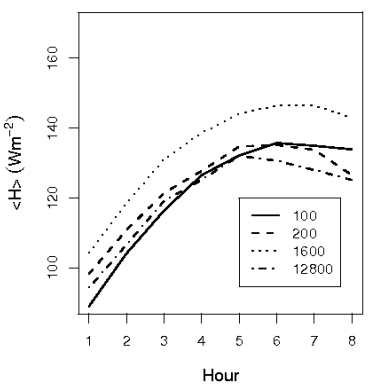

(c)

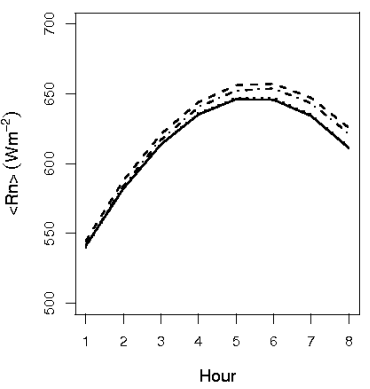

(b)

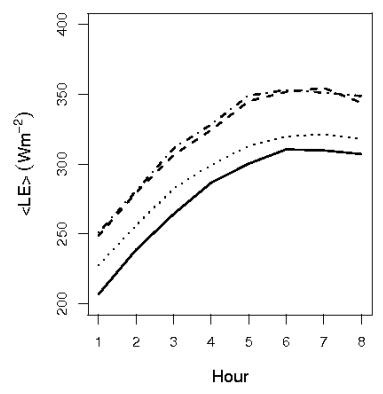

(d)

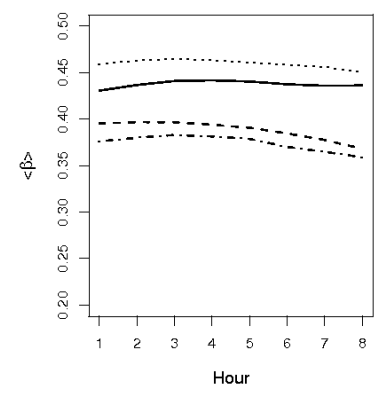

Fig. 6. Time series of the spatially averaged (a) surface heat flux [W $\mathrm{m}^{-2}$ ] and (b) latent heat flux $\left[\mathrm{W} \mathrm{m} \mathrm{m}^{-2}\right]$ (c) net radiation $\left[\mathrm{W} \mathrm{m}^{-2}\right]$ and (d) Bowen ratio $(\beta,[-])$ for each level of decomposition.

creased as the surface length scale decreased. In our case, we observe that for large and small surface scales characteristic of more surface homogeneity, the latent heat flux dominates.

As evident from $<$ LE $>$ flux, the simulations appear to diverge into either a wet or a dry regime (at least so far as the atmospheric fields are concerned). It is important to note that this behavior is not due to any soil moisture limitation across the cases. This divergence into the different $<\mathrm{LE}>$ states is not apparent in the $\langle H>$ timeseries, implying that the surface heterogeneity most directly affects the latent heat flux. The sensible heat flux is only higher for the intermediate scale, while the original surface fields are more similar to the largest and smallest cases of $\langle H\rangle$. This variation in $<H>$ as a function of scale is not due simply to a higher surface temperatures (Fig. 4). This behavior for $\langle H\rangle$ is consistent with the results of Huang and Margulis (2009), assuming the intermediate scales can be viewed as more "organized" than either the larger or smaller surface heterogeneity cases.

In addition, the energy balance ratio $\left(\mathrm{EBR}=(\mathrm{LE}+H) / R_{\mathrm{n}}\right)$ is examined as a possible cause for the dynamics of the turbulent fluxes as a function of the length scales. The spatial average of the ratio is 0.65 in the original case and $0.71,0.69,0.71$ for the smallest to largest length scale scenarios. The spatial standard deviation of the ratio was 0.22 in all cases. Assuming a soil heat flux on the order of $30 \%$ of the net radiation, the closure of the energy balance is fairly consistent across all length scales. This 

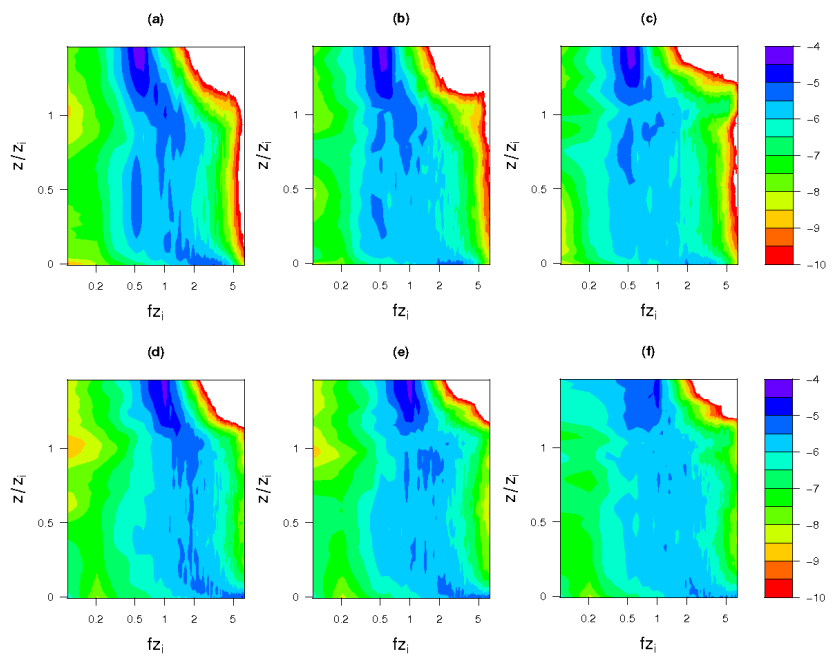

Fig. 7. (Top) Normalized spectra [P m] for the control simulation employing the observed (unfiltered) conditions. (a) Vertical velocity (b) air temperature (c) specific humidity and (bottom) normalized cospectra for (d) vertical velocity and air temperature (e) vertical velocity and specific humidity and (f) air temperature and specific humidity.

implies that the dynamics observed here are not a function of energy balance closure issues.

\subsection{Surface-atmosphere interactions}

We calculate profiles of horizontally averaged spectra and cospectra to explore the response of boundary layer structures to surface heterogeneity. Spectra and cospectra are calculated for each horizontal line section in a direction parallel to the mean wind (and shear). The spectra are then averaged to obtain the mean horizontal spectra as a function of height as shown in the figures. Spectra for the control simulation are shown as a function of height in Fig. 7 for the vertical velocity, air temperature and specific humidity. The spectra are normalized by the spatial variance at each height and are plotted as $f E(f)$ where $f$ is the frequency and $E(f)$ is the energy. In addition, the spectra are plotted as a normalized frequency (normalized by the boundary layer height $z_{i}$ ). The vertical coordinate is also shown as a fraction of the $z_{i}$, which was determined from the largest vertical temperature change in the spatially averaged profile for each simulation.

Each of the spectra show generally the same dynamic, which includes a significant contribution at high frequencies near the surface. This high frequency component falls off quickly with height and remains fairly uniform up to the base of the inversion layer. The high frequency component becomes greatly diminished above the inversion height (approximately $1300 \mathrm{~m}, z / z_{i}=1$ ), likely a direct influence of the increased stability, which rapidly suppresses the smaller scale oscillations and more slowly damps the larger, more rigorous and organized updrafts. In addition to the spectra, (a)

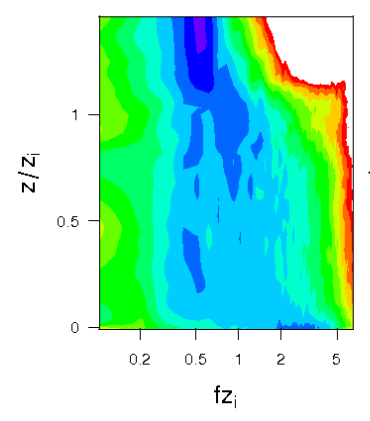

(c)

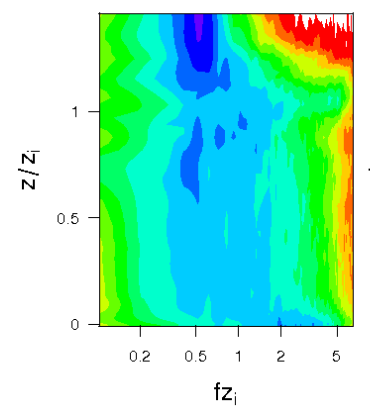

(b)

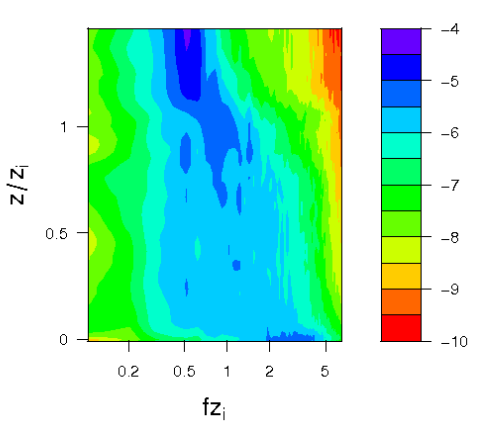

(d)

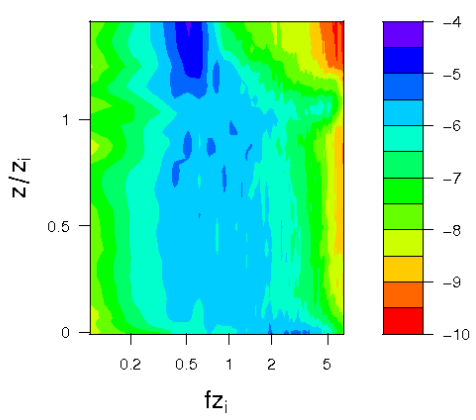

Fig. 8. Normalized copectra [P m] for control simulation. (a) Surface temperature and air temperature (b) surface sensible heat and air temperature (c) soil moisture and air specific humidity (d) surface latent heat and specific humidity.

the cospectra between the vertical velocity and air temperature $(\tilde{w} \tilde{T}$, the predominant component of buoyancy flux), vertical velocity and humidity ( $\tilde{w} \tilde{q}$, the water vapor flux) and temperature and humidity $(\tilde{T} \tilde{q})$ are also shown in Fig. 7 . The variation in the shapes of the cospectra follow a similar variation with height as do the spectra themselves. The cospectra paint a picture of boundary layer eddy transport of heat and moisture of the same scale as the eddies themselves, a logical result since the eddies themselves accomplish the transport.

The nature of the surface-atmosphere interactions is investigated using the cospectra between the surface and atmospheric fields (Fig. 8). The modal frequency of the cospectra are similar, no matter whether surface fluxes or the scalars themselves are employed, and all the cospectra exhibit variability with height similar to that in the atmospheric spectra. However, the scalar-scalar cospectra illustrate more variability with height than the surface flux-scalar spectra. This is taken to be illustrative of the impact of the fluxes on the atmospheric scalar remaining significant across heights whereas the surface scalar-atmospheric scalar covariation is less robust (Albertson and Parlange, 1999). Physically, this corresponds to the notion that the fluxes themselves most directly drive the moist, buoyant updraft cores, while the connection of these cores to the surface fields themselves is more indirect. 

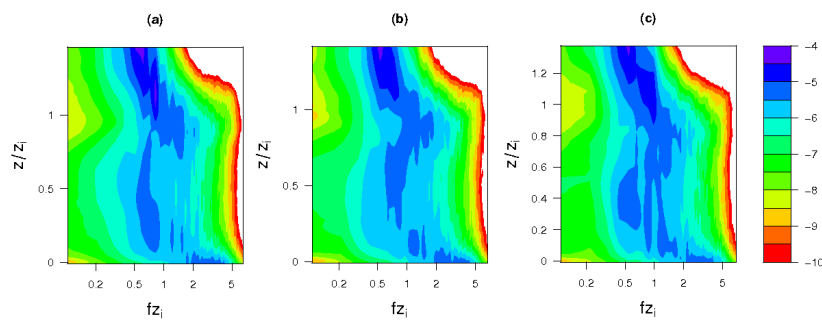

(d)
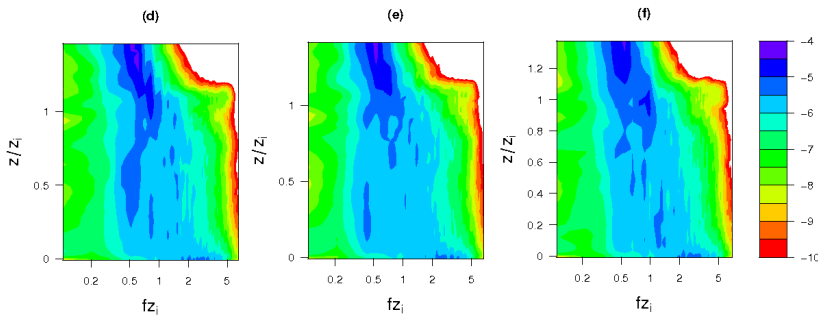

(g)
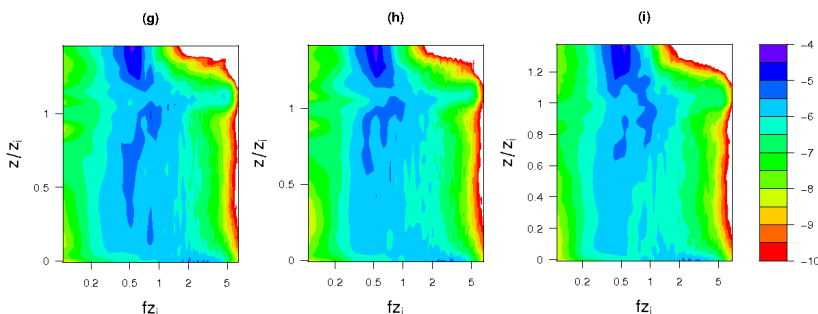

Fig. 9. Normalized spectra [P $\mathrm{m}]$ for the low wind speed scenario as a function of length scale increasing from left to right $(\mathbf{a}-\mathbf{c})$ vertical velocity $(\mathbf{d}-\mathbf{f})$ air temperature and $(\mathbf{g}-\mathbf{i})$ specific humidity.

In order to ascertain how the transport of water and temperature might vary under different length scales of surface heterogeneity, we examine the horizontally averaged Fourier spectra for the vertical velocity, temperature and specific humidity (Fig. 9).

In addition, we examine the height-dependent cospectra between surface conditions and atmospheric fields. Specifically, we calculated surface temperature - air temperature, surface sensible heat flux - air temperature, soil moisture specific humidity and surface latent heat - specific humidity cospectra (Fig. 10). The left columns represent the smallest length scale, while the right columns show the spectra for the largest length scale.

In each case in Figs. 9 and 10, the spectra generally show a maximum in the higher frequencies near the surface. As the eddies move away from the surface, we see an increasing role played by the largest eddies. Above approximately $z / z_{i}=0.1$, the spectra remain relatively constant until the top of the well-mixed layer is reached. Near the base of the entrainment zone, higher frequency eddies (particularly for the specific humidity) play an additional role. The physical mechanisms responsible for this dynamic are unclear. Above the inversion height, we again see the predominant role played by the penetrative updrafts that likely originated from the strongest eddies. As discussed above, here too we (a)

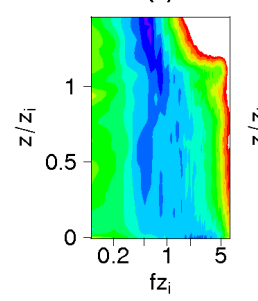

(d)

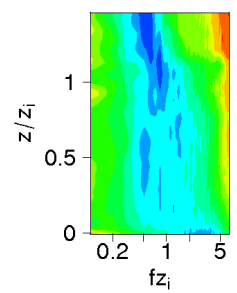

(g)

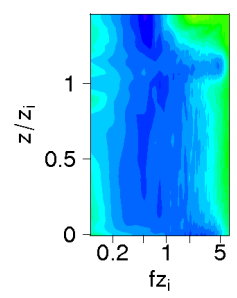

(j)
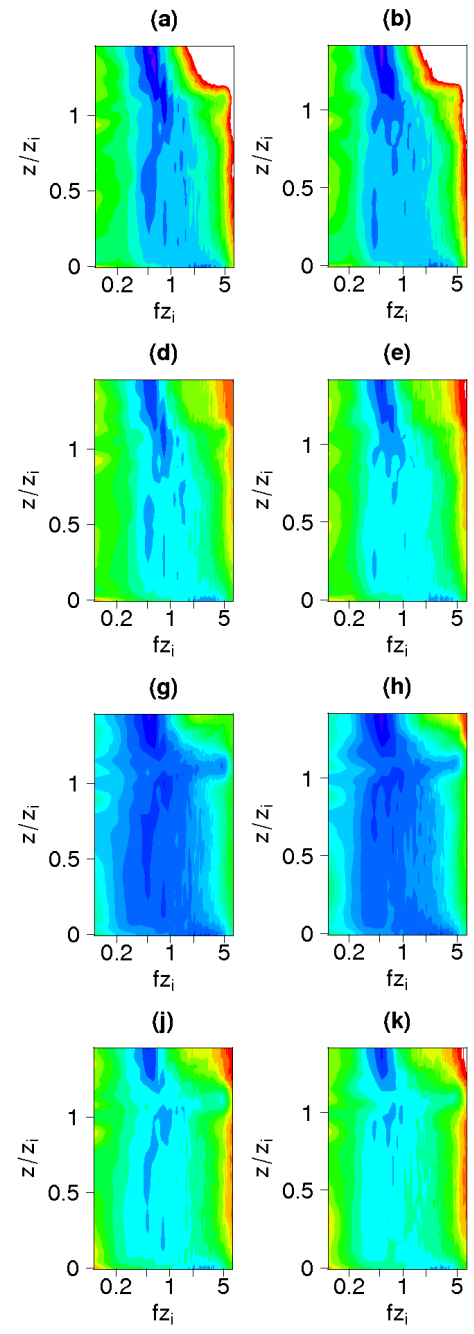

(e)

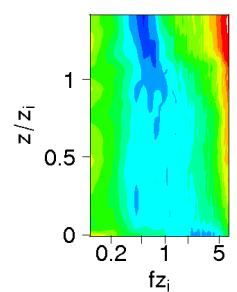

(h)

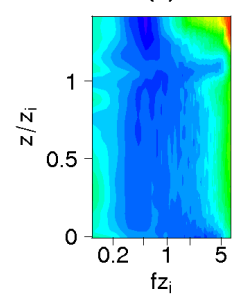

(k)

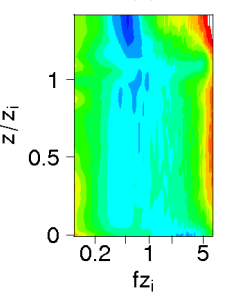

(c)

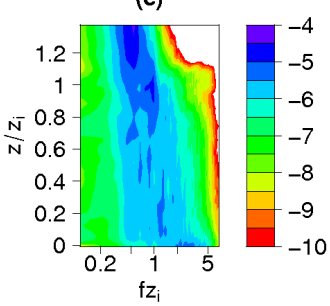

(f)

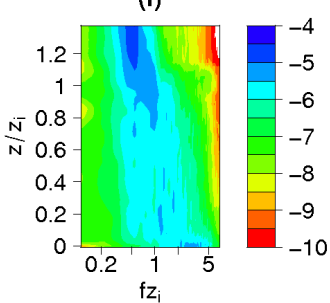

(i)

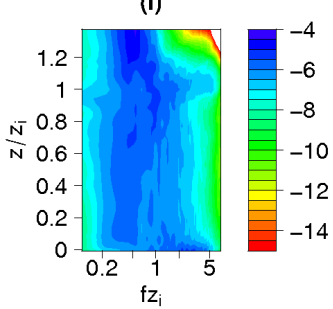

(I)

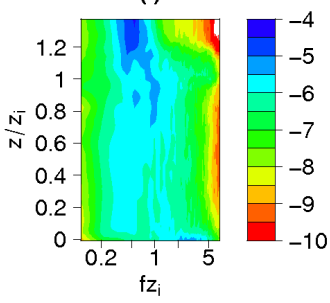

Fig. 10. Normalized copectra $[\mathrm{P} \mathrm{m}]$ for low wind speed scenario as a function of length scale increasing from left to right (a-c) surface temperature and air temperature (d-f) surface sensible heat and air temperature $(\mathbf{g}-\mathbf{i})$ soil moisture and air specific humidity $(\mathbf{j}-\mathbf{l})$ surface latent heat and specific humidity.

see a rapid decrease in the energy carried by small eddies, as they rapidly decay in the stable inversion layer.

The fact that all the spectra show generally the same shape and the same contribution from eddies of different sizes is somewhat surprising. Regardless of whether the surface length scale is much smaller or much larger than the boundary layer depth there is little variability in the spectra. This implies that the degree of surface heterogeneity has little to no impact on the structure of the turbulent flow within the boundary layer. While the magnitudes of the scalars and surface fluxes vary with the scale of heterogeneity (Fig. 6), the atmospheric response appears to be insensitive to the particular spatial configuration of these quantities. 


\subsection{Combined effects of surface heterogeneity and wind speed variation}

In addition to examining the impacts of surface heterogeneity, we wish to examine the combined impacts of altering horizontal wind speeds and the length scale of surface heterogeneity. Therefore, we use the initial sounding as the low wind speed condition, then add $3 \mathrm{~m} \mathrm{~s}^{-1}$ to the zonal wind to make an intermediate case, along with an additional $3 \mathrm{~m} \mathrm{~s}^{-1}$ for a high wind speed scenario. These values were chosen as substantial increases, although physically realistic values by which to assess the impacts of changes in the mean horizontal wind forcing.

The mean and variance for surface temperature and soil moisture for each wind speed and horizontal length scale are given in Table 1. The table illustrates interesting dynamics not immediately obvious from viewing the full PDFs corresponding to the original wind speed scenarios (Fig. 4). Across all wind speeds, for the band pass filtered scenarios the finest and coarsest scales exhibit similar values of mean surface temperature and moisture. However, the variance is significantly larger in the coarser spatial scales. As expected, with increasing wind speed the surface temperature decreases, regardless of the scale. The simulations employing the full, unfiltered land surface properties closely resemble the intermediate scale in terms of the mean temperature, but the spatial variance at the end of the simulation is generally about twice as large. Mean surface moisture is not sensitive to scale and decreases only slightly with increasing wind speeds. The strongest moisture fluxes in the range of 300$350 \mathrm{~W} \mathrm{~m}^{-2}$ do not result in a significant drying of the soil after only eight hours. Differences in soil moisture would presumably become more evident in successive days, however, as the larger latent heat fluxes in the $200 \mathrm{~m}$ and $12.8 \mathrm{~km}$ scale simulations manifest themselves as lower soil moisture values.

The trends in the spatial variance across length scales (Table 1) could possibly be due to the development of local internal boundary layers. Thus at larger spatial scales, the large patches either enhance or decrease the turbulent dynamics, e.g. a binary classification develops where the local wind is either fast or slow. This leads to a relatively large spatial variance when considering the whole domain. In the smaller length scale cases, these internal layers never develop and thus the overall spatial variance is decreased relative to the larger length scale cases. This trend is shown regardless of the wind speed scenario. All of the filtered cases exhibit smaller spatial variances than the observed case, with the largest scale scenario having approximately $80 \%$ of the observed spatial variance. This illustrates the non-linear interactions of the different scales combining to enhance the spatial variance relative to the cases with only one length scale evident.
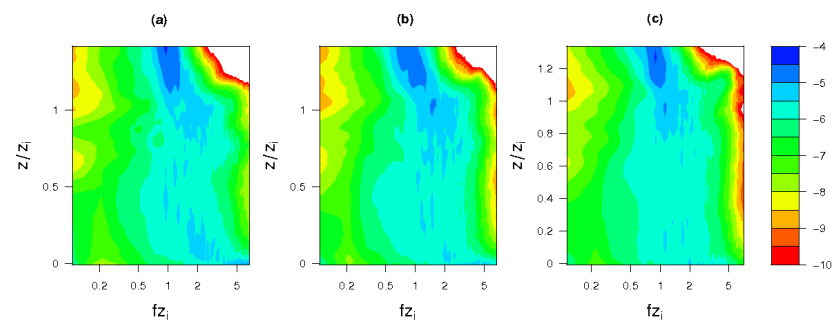

Fig. 11. Normalized copectra $[\mathrm{P} \mathrm{m}]$ for the intermediate scale surface heterogeneity vertical velocity and air temperature for (a) low (b) medium and (c) high wind speed scenarios.

The atmospheric cospectra $(\tilde{w} \tilde{T})$ are shown in Fig. 11 for the intermediate scale of surface heterogeneity for each wind speed scenario. The other cospectra $(\tilde{w} \tilde{q}$ and $\tilde{T} \tilde{q})$ demonstrated similar behavior and are not shown. With increasing wind speed, the high frequency contribution near the surface diminishes. However, above $z / z_{i} \approx 0.1$ the impact of altering the horizontal wind speed is not observed.

Our results indicate that the variation of the surface length scales has very little impact on the configuration of the turbulent flow. However, changing the surface length scale alters the magnitude and partitioning of the surface turbulent fluxes, a result obvious from Fig. 6. Variations in the surface fluxes ultimately translate into variations in the spatially averaged scalar profiles (Fig. 12). The cases showing higher LE fluxes are more moist, while the larger $H$ in the intermediate scale results in a warmer temperature profile. The partitioning of the surface fluxes ultimately affects boundary layer depth as well. Boundary layer depth in Fig. 12 is largely determined by the time-integrated buoyancy, the largest component being $H$ in Fig. 6 . The $1600 \mathrm{~m}$ scale consistently has the largest values of $H$ over the course of the simulation, so unsurprisingly it has the deepest boundary layer.

Vertical profiles of spatial variance in each of the winds and the scalar fields of temperature and humidity are shown in Figs. 13 and 14 respectively. The variance of temperature in the mixed layer is remarkably similar across all scales, while moisture and vertical velocity variances vary significantly. Vertical velocity variance is often taken as a proxy for mean boundary layer turbulent intensity, and the greatest variances are associated with the largest surface sensible heat fluxes (Fig. 6) and the deepest boundary layers. The relationship between $\sigma_{\tilde{w}}^{2}$ and boundary layer depth is evident in the profiles of $\sigma_{\tilde{T}}^{2}$ and $\sigma_{\tilde{q}}^{2}$. Thus the boundary layer energetics are tied to surface heterogeneity via the partitioning between $H$ and LE, for which $H$ drives the turbulent eddies. Figures 14 and 6 show that the largest scale is the warmest and driest, has the largest $H$, and hence is the most energetic.

The intermediate scale generally exhibits lower spatial variance than the other cases, reaching a maximum at a higher ABL height. The other cases show increased ABL heights at the smallest scales of surface heterogeneity, 
(a)

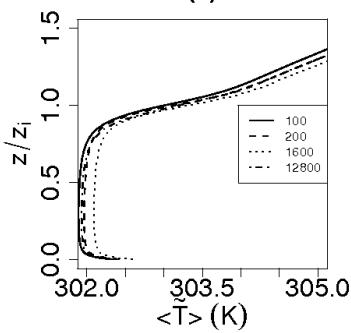

(c)

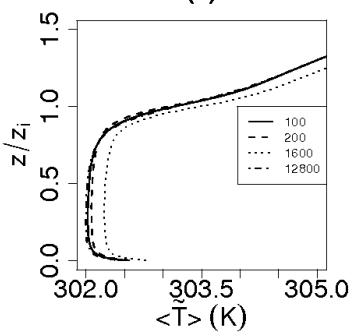

(e)

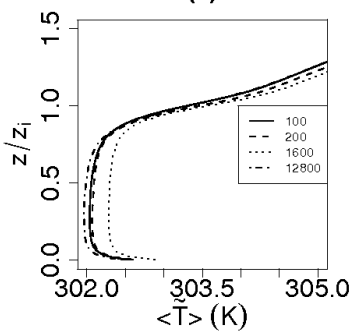

(b)

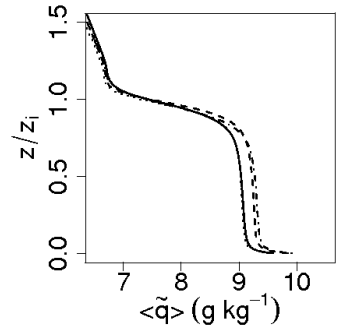

(d)

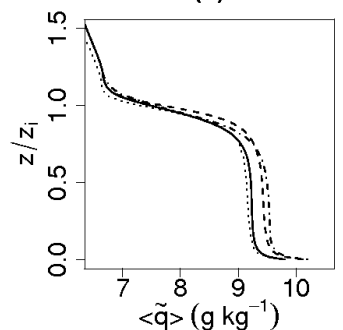

(f)

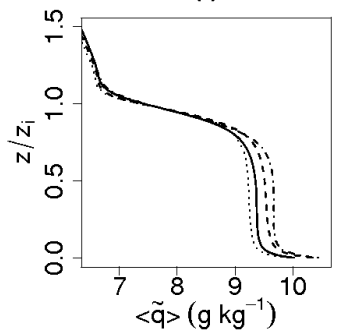

Fig. 12. Spatially averaged vertical scalar profiles for (left) air temperature $[\mathrm{K}]$ (right) specific humidity $\left[\mathrm{g} \mathrm{kg}^{-1}\right]$ for $(\mathbf{a}, \mathbf{b})$ low, $(\mathbf{c}, \mathbf{d})$ intermediate and $(\mathbf{e}, \mathbf{f})$ high wind speeds.

decreasing with the scale. Thus, the temperature seems to be the less sensitive to the impacts of surface heterogeneity than water vapor, which is in contrast to several previous studies which show temperature playing a more dominant role (Avissar et al., 1998; Huang and Margulis, 2009). However, Patton et al. (2005) found that this sensitivity depends upon the scale of the surface patches, a result that may be indicative of different transport efficiencies for $T$ and $q$ which varies as a function of both mean wind speed and the spatial scale of surface heterogeneity. Scalar dissimilarity for temperature, water vapor and carbon dioxide was also found in Huang et al. (2009). Our results are consistent with notions of scalar dissimilarity, a clear physical explanation for the scale-dependent differences in the temperature and moisture variances is elusive.

In addition, our results show that as wind speed increases the spatial variance decreases significantly. This is presumably due to the impact of the mean horizontal forcing inhibiting the deviations from the mean state.

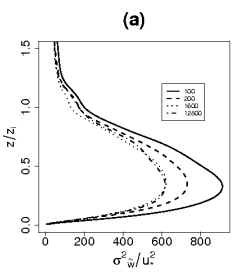

(d)

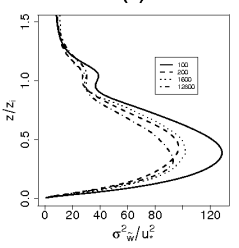

(g)

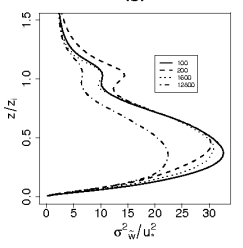

(b)

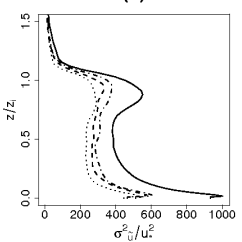

(e)

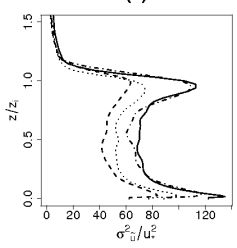

(h)

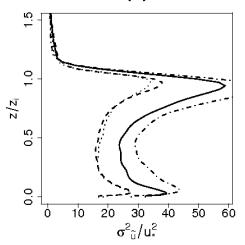

(c)

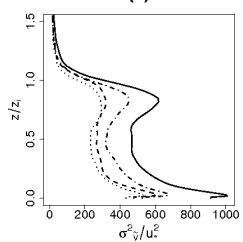

(f)

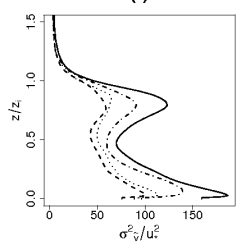

(i)

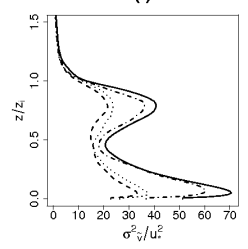

Fig. 13. Spatial variances of scalars (a) vertical wind $\left[\left(\mathrm{m} \mathrm{s}^{-1}\right)^{2}\right]$ (b) temperature $[\mathrm{K}]$ (c) specific humidity $\left[\left(\mathrm{g} \mathrm{kg}^{-1}\right)^{2}\right]$ (d) horizontal wind speed $\left[\left(\mathrm{m} \mathrm{s}^{-1}\right)^{2}\right]$ for (top) low, (middle) intermediate and (bottom) high wind speeds simulations.

\section{Conclusions}

It is often proposed that the dominant mechanism of surfaceatmosphere interactions is modulated via changes in net radiation that alters the available energy (Friedrich et al., 2000; Eltahir, 1989). Of course, as land cover type is altered, the variation in surface net radiation will be a dominant factor in determining the coupled response of the land-atmosphere system. However, Jones and Brunsell (2009) observed variations in soil moisture-precipitation feedbacks resulting from a change in the partitioning between latent and sensible heat, with little change in the $\left\langle R_{\mathrm{n}}\right\rangle$. Similarly, Teuling and Seneviratne (2008) showed that there was little change in the surface albedo corresponding with the European heat wave of 2003. If these results are correct, then a different mechanism is responsible for maintaining surface-atmosphere feedbacks (at least in the case of feedbacks mediated by precipitation).

We have examined the role of land-atmosphere interactions under heterogeneous surface conditions in order to investigate to what extent changes in net radiation are responsible for altering surface-atmosphere transport. Using 12 coupled land surface - large eddy simulation scenarios with 4 different length scales of surface variability under 3 different horizontal wind speeds, we have observed little variation in net radiation across the model runs.

The variation in responses across the simulations were largely due to a change in the partitioning of the surface energy between sensible and latent heat flux. We find that for 
(a)

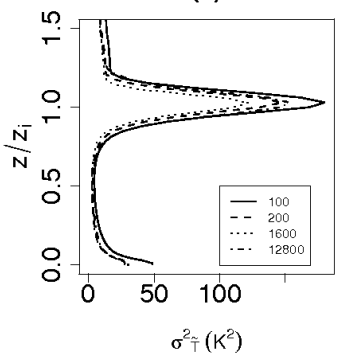

(c)

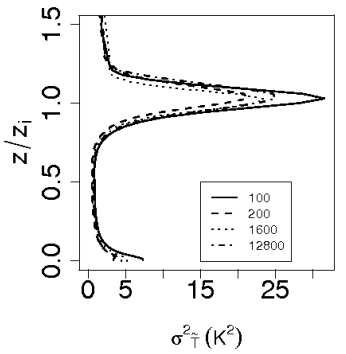

(e)

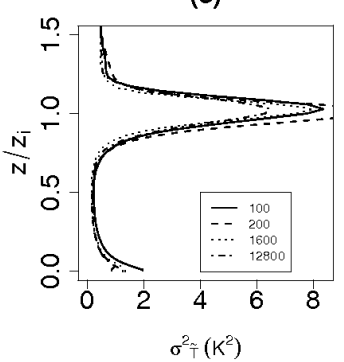

(b)

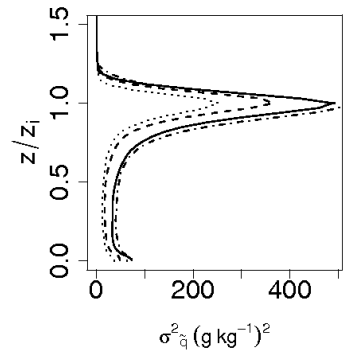

(d)

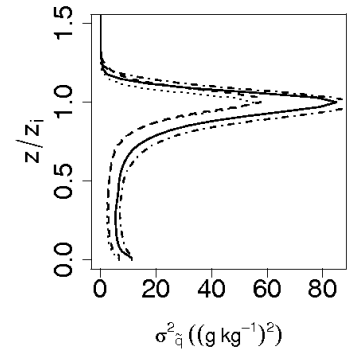

(f)

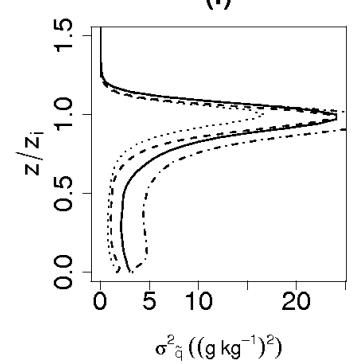

Fig. 14. Spatial variances of scalars (a) temperature $[\mathrm{K}]$ and (b) specific humidity $\left[\left(\mathrm{g} \mathrm{kg}^{-1}\right)^{2}\right]$ for (top) low, (middle) intermediate and (bottom) high wind speeds simulations.

intermediate surface length scales, the sensible heat flux is dominant. For smaller and larger scales of surface variability, which can be viewed as being more homogeneous, the latent heat flux becomes increasingly important, and $\beta$ is decreased.

The changes in the surface energy partitioning impacts turbulent transport throughout the boundary layer. We find that air temperature is less sensitive to surface heterogeneity than water vapor. From this result, we speculate that the role of surface heterogeneity is to modify the local temperature gradients in order to maximize convective heat fluxes. This effect is observed in the intermediate length scale simulations which are typically warmer and drier than the other simulations. Under more homogeneous surface conditions at the largest and smallest length scales of variability, the latent heat flux is maximized. This partitioning of surface energy alters boundary layer energetics, vertical transport, and ultimately, boundary layer depth.
Although the surface fluxes in the simulations have different spatial scales, the atmosphere processes the fluxes in a similar manner regardless of the length scale of surface heterogeneity. This is observed through the spectral analysis. The spectra indicate that, in general, the surface fluxes are more closely coupled with atmospheric scalars than are the surface quantities. Our results corroborate previous results by Albertson and Parlange (1999) that fluxes are blended higher in the atmosphere than scalars.

Contrary to some prior results which have shown pronounced impacts by the land surface on the nature of turbulent structure, our results have failed to indicate such dynamics. There are a few potential reasons for this. First, perhaps there was not enough spatial variation in the surface fields to incite an atmospheric response. However, given the range of values (e.g. the range of surface temperature being approximately $20 \mathrm{~K}$ ), this seems unlikely. Another potential impact could be the length scales of the filters chosen here are insufficient to observe a change. The range of filters used here was specifically chosen to encompass the range of previous studies: much smaller than the boundary layer, on the order of the boundary layer and much larger than the boundary layer. The largest scales here are on the order of Avissar et al. (1998), Shen and Leclerc (1995) and Letzel and Raasch (2003) where length scales of 5-10 km showed pronounced effects. This leaves a few other considerations, such as the overall domain not being sufficiently large. Another possibility is simply the nature of the patches and surface heterogeneity at the time of observation during the CLASIC field campaign were not favorable for such interactions.

Since our results suggest that the role of the surface heterogeneity is to alter the energy balance partitioning, we expect that these results will vary based on different strategies of distributing the energy between the surface and the atmosphere. Therefore, we recommend that further research be conducted into the nature of different vegetation types and phenological patterns be examined for altering the conversion of net radiation into turbulent heat fluxes and the potential impacts this may have on boundary layer dynamics.

Our results are important for understanding the mechanistic pathways for how land surface variability translates to differences in boundary layer properties. This process-level insight is crucial for understanding local land-atmosphere responses to regional and global climate change. Under the identical atmospheric conditions, we have observed different responses in term of water and heat fluxes.

Acknowledgements. We would like to thank the National Science Foundation EPSCoR KAN0061396/ KAN006263 for funding this research.

Edited by: J. Rinne 


\section{References}

Albertson, J. D. and Parlange, M. B.: Natural integration of scalar fluxes from complex terrain, Adv. Water Res., 23, 239-252, 1999.

Albertson, J. D., Kustas, W. P., and Scanlon, T. M.: Large-eddy simulation over heterogeneous terrain with remotely sensed land surface conditions, Water Res. Res., 37, 1939-1953, 2001.

Anderson, M. C., Kustas, W. P., and Norman, J. M.: Upscaling and downscaling - a regional view of the soil-plant-atmosphere continuum, Agronomy Journal, 95, 1408-1423, 2003.

Avissar, R., Eloranta, E. W., Gurer, K., and Tripoli, G. J.: An evaluation of the large-eddy simulation option of the Regional Atmospheric Modeling System in simulating a convective boundary layer: A FIFE case study, J. Atmos. Sci., 55, 1109-1130, 1998.

Bertoldi, G., Kustas, W. P., and Albertson, J. D.: Estimating spatial variability in atmospheric properties over remotely sensed land surface conditions, J. Appl. Meteorol. Climatol., 47, 2147-2165, doi:10.1175/2007JAMC1828.1, 2008.

Bou-Zeid, E., Meneveau, C., and Parlange, M. B.: Largeeddy simulation of the neutral atmospheric boundary layer flow over heterogeneous surfaces: blending height and effective surface roughness, Water Resour. Res., 40, W02505, doi:10.1029/2003WR002, 2004.

Brunsell, N. A. and Gillies, R. R.: Scale issues in land-atmosphere interactions: a review, with implications for remote sensing of the surface energy balance, Agr. Forest Meteorol., 117, 203-221, 2003.

Chehbouni, A., Njoku, E. G., Lhomme, J. P., and Kerr, Y. H.: Approaches for averaging surface parameters and fluxes over heterogeneous terrain, J. Climate, 8, 1386-1393, 1995.

Chow, F. K., Weigel, A. P., Street, R. L., Rotach, M. W., and Xue, M.: High-resolution large-eddy simulation of flow in a steep alpine valley. Part I: Methodology, verification and sensitivity experiments, J. Appl. Meteorol. Climatol., 45, 63-86, 2006.

Claussen, M.: Area-averaging of surface fluxes in a neutrally stratified, horizontally inhomogeneous atmospheric boundary layer, Atmos. Environ., 24a, 1349-1360, 1990.

Courault, D., Drobinski, P., Brunet, Y., Lacarrere, P., and Talbot, C.: Impact of surface heterogeneity on a buoyancy-driven convective boundary layer in light winds, Bound. Lay. Meteorol., 124, 383403, doi:10.1007/s10546-007-9172-y, 2007.

Deardorff, J. W.: Stratocumulus-capped mixed layers derived from a three-dimensional model, Bound. Lay. Meteorol., 18, 495-527, 1980.

Eltahir, E. A. B.: A feedback mechanism in annual rainfall, central Sudan, J. Hydrol., 110, 323-334, 1989.

Foken, T.: The energy balance closure problem: An overview, Ecol. Appl., 18, 1351-1367, 2008.

Friedrich, K., Molders, N., and Tetzlaff, G.: On the influence of surface heterogeneity on the Bowen-ratio: A theoretical case study, Theor. Appl. Climatol., 65, 181-196, 2000.

Gillies, R. R. and Carlson, T. N.: Thermal remote sensing of surface soil water content with partial vegetation cover for incorporation into climate models, J. Appl. Meteorol., 34, 745-756, 1995.

Gillies, R., Carlson, T., Cui, J., Kustas, W., and Humes, K.: A verification of the "triangle" method for obtaining surface soil water content and energy fluxes from remote measurements of the Normalized Difference Vegetation Index (NDVI) and surface radiant temperature, Int. J. Remote Sens., 18, 3145-3166, 1997.
Hadfield, M. G., Cotton, W. R., and Pielke, R. A.: Large-eddy simulations of thermally forced circulations in the convective boundary layer. Part I: a small-scale circulation with zero wind, Bound. Lay. Meteorol., 57, 79-114, 1991.

Hadfield, M. G., Cotton, W. R., and Pielke, R. A.: Large-eddy simulations of thermally forced circulations in the convective boundary layer. Part 2: the effect of changes in wavelength and wind speed, Bound. Lay. Meteorol., 58, 307-327, 1992.

Hechtel, L. M., Moeng, C. H., and Stull, R. B.: The effects of nonhomogeneous surface fluxes on the convective boundary layer: a case study using large eddy simulation, J. Atmos. Sci., 47, 1721$1741,1990$.

Huang, H.-Y. and Margulis, S. A.: On the impact of surface heterogeneity on a realistic convective boundary layer, Water Resour. Res., 45, W06512, doi:10.1029/2008WR007175, 2009.

Huang, J., Lee, X., and Patton, E. G.: A Modelling Study of Flux Imbalance and the Influence of Entrainment in the Convective Boundary Layer, Bound.-Lay. Meteorol., 127, 273-292, 2008.

Huang, J., Lee, X., and Patton, E. G.: Dissimilarity of Scalar Transport in the Convective Boundary Layer in Inhomogeneous Landscapes, Boundary Layer Meteorology, 130, 327-345, doi:10.1007/s10546-009-9356-8, 2009.

Jones, A. R. and Brunsell, N. A.: Energy balance partitioning and net radiation controls on soil moisture-precipitation feedbacks, Earth Interactions, 13, 1-25, 2009.

Khanna, S. and Brasseur, J. G.: Analysis of Monin-Obukhov similarity theory from large-eddy simulation, J. Fluid Mech., 345, 251-286, 1997.

Koster, R. and Suarez, M.: Modeling the land surface boundary in climate models as a composite of independent vegetation stands, J. Geophys. Res., 97, 2697-2715, 1992.

Kumar, P. and Foufoula-Georgiou, E.: A multicomponent decomposition of spatial rainfall fields. 1. Segregation of large- and small-scale features using wavelet transforms, Water Resour. Res., 29, 2515-2532, 1993.

Kustas, W. P. and Albertson, J. D.: Effects of surface temperature contrast on land-atmosphere exchange: A case study form Monsoon 90, Water Resour. Res., 39, 1159, doi:10.1029/2001WR001226, 2003.

Lamaud, E. and Irvine, M.: Temperature-humidity dissimilarity and heat-to-water-vapour transport efficiency above and within a pine forest canopy: The role of the Bowen ratio, Bound.-Lay. Meteorol., 120, 87-109, doi:10.1007/s10546-005-9032-6, 2006.

Letzel, M. O. and Raasch, S.: Large eddy simulation of thermally induced oscillations in the convective boundary layer, J. Atmos. Sci., 60, 2328-2341, 2003.

Lhomme, J. P., Chehbouni, A., and Monteny, B.: Effective parameters of surface energy balance in heterogeneous landscape, Bound. Lay. Meteorol., 71, 297-309, 1994.

Lin, C. L. and Glendening, J. W.: Large eddy simulation of an inhomogeneous atmospheric boundary layer under neutral conditions, J. Atmos. Sci., 59, 2479-2497, 2002.

Mahrt, L.: Surface heterogeneity and vertical structure of the boundary layer, Bound. Lay. Meteorol., 96, 33-62, 2000.

Mason, P. J.: The formation of areally-averaged roughness lengths, Q. J. Roy. Meteorol. Soc., 114, 399-420, 1988.

Moeng, C.-H. and Wyngaard, J. C.: Spectral analysis of large-eddy simulations of the convective boundary layer, J. Atmos. Sci., 45, 3573-3587, 1988. 
Molod, A., Salmun, H., and Waugh, D. W.: A new look at modeling surface heterogeneity: extending its influence in the vertical, J. Hydrometeorol., 4, 810-825, 2003.

Noilhan, J. and Planton, S.: A simple parameterization of land surface processes for meteorological models, Mon. Weather Rev., 117, 536-549, 1989.

Patton, E., Sullivan, P., and Moeng, C.: The influence of idealized heterogeneity on wet and dry planetary boundary layers coupled to the land surface, J. Atmos. Sci., 62, 2078-2097, 2005.

Prabha, T. V., Karipot, A., and Binford, M. W.: Characteristics of secondary circulations over an inhomogeneous surface simulated with large-eddy simulation, Bound. Lay. Meteorol., 123, 239261, doi:10.1007/s10546-006-9137-6, 2007.

Raasch, S. and Harbusch, G.: An analysis of secondary circirculations and their effects caused by small-scale surface inhomogeneities using large-eddy simulation, Bound. Lay. Meteorol., 101, 31-59, 2001.

Raupach, M. and Finnigan, J.: Scale issues in boundary-layer meteorology: surface energy balances in heterogeneous terrain, Hydrol. Process., 9, 589-612, 1995.

Shen, S. and Leclerc, M.: How Large Must Surface Inhomogeneities Be Before They Influence the Convective Boundary Layer Structure?: A Case Study, Q. J. Roy. Meteorol. Soc., 121, 1209-1228, 1995.

Stevens, B. and Lenschow, D.: Observations, experiments and large eddy simulation, B. Am. Meteorol. Soc., 82, 283-294, 2001.

Teuling, A. J. and Seneviratne, S. I.: Contrasting spectral changes limit albedo impact on land-atmosphere coupling during the 2003 European heat wave, Geophys. Res. Lett., 35, L03401, doi:10.1029/2007GL032778, 2008.

Timmermans, W. J., Bertoldi, G., Albertson, J. D., Olioso, A., Su, Z., and Gieske, A. S. M.: Accounting for atmospheric boundary layer variability on flux estimation from RS observations, Int. J. Remote Sens., 29, 5275-5290, doi:10.1080/01431160802036383, 2008.
Twine, T., Kustas, W., Norman, J., Cook, D., Houser, P., Meyers, T., Prueger, J., Starks, P., and Wesely, M.: Correcting eddycovariance flux underestimates over a grassland, Agr. Forest Meteorol., 103, 279-300, 2000.

van der Kwast, J., Timmermans, W., Gieske, A., Su, Z., Olioso, A., Jia, L., Elbers, J., Karssenberg, D., and de Jong, S.: Evaluation of the Surface Energy Balance System (SEBS) applied to ASTER imagery with flux-measurements at the SPARC 2004 site (Barrax, Spain), Hydrol. Earth Syst. Sci., 13, 1337-1347, doi:10.5194/hess-13-1337-2009, 2009.

Vinkovic, I., Aguirre, C., and Simoens, S.: Large-eddy simulation and Lagrangian stochastic modeling of passive scalar dispersion in a turbulent boundary layer, J. Turbulence, 7, 1-14, 2006.

Weigel, A. P., Chow, F. K., Rotach, M. W., Street, R. L., and Xue, M.: High-resolution large-eddy simulation of flow in a steep alpine valley. Part II: Flow structure and heat budgets, J. Appl. Meteorol. Climatol., 45, 87-107, 2006.

Williams, C. A., Scanlon, T. M., and Albertson, J. D.: Influence of surface heterogeneity on scalar dissimilarity in the roughness sublayer, Bound.-Lay. Meteorol., 122, 149-169, 2007.

Xue, M., Droegemeier, K. K., and Wong, V.: The Advanced Regional Prediction System (ARPS) - A multi-scale nonhydrostatic atmospheric simulation and prediction model. Part 1: Model dynamics and verification, Meteorol. Atmos. Phys., 75, 161-193, 2000.

Xue, M., Droegemeier, K. K., and Wong, V.: The Advanced Regional Prediction System (ARPS) - A multi-scale nonhydrostatic atmospheric simulation and prediction model. Part 2: Model physics and applications, Meteorol. Atmos. Phys., 76, 143-165, 2001. 